\title{
Exigências Agroclimáticas para a Cultura do Feijão (Phaseolus vulgaris L.)
}

\author{
Vinicius Gabriel Caneppele Pereira ${ }^{2}$, Diego José Gris ${ }^{3}$, Thiago Marangoni ${ }^{4}$, Jianice Pires \\ Frigo $^{5}$, Késia Damaris de Azevedo ${ }^{6}$, Anderson Eduardo Grzesiuck ${ }^{7}$
}

\footnotetext{
${ }^{1}$ Aceito para publicação no $1^{\circ}$ trimestre de 2014

${ }^{2}$ Acadêmicos em Agronomia pela Universidade Federal do Paraná - UFPR, Setor Palotina, Brasil, viniciuscpo@hotmail.com;

${ }^{3}$ Acadêmicos em Agronomia pela Universidade Federal do Paraná - UFPR, Setor Palotina, Brasil, diegojgris@gmail.com;

${ }^{4}$ Acadêmicos em Agronomia pela Universidade Federal do Paraná - UFPR, Setor Palotina, Brasil, marangoni1228@gmail.com;
}

${ }^{5}$ Graduanda em agronomia na Universidade Regional Integrada do Alto Uruguai e das Missões - URI Campus de Santiago - RS, Brasil, jifrigo@ yahoo.com;

${ }^{6}$ Graduada em Tecnologia em Biotecnologia na Universidade Federal do Paraná, Palotina - PR, Brasil, kesia.damaris@gmail.com,

${ }^{7}$ Acadêmicos em Agronomia pela Universidade Federal do Paraná - UFPR, Setor Palotina, Brasil, anderson.grzesiuck@gmail.com.

\section{Resumo}

O conhecimento das exigências agroclimáticas das culturas é uma ferramenta que auxilia o planejamento agrícola, visando maior produtividade, rentabilidade e diminuição de perdas por fatores climáticos. Dentre os elementos climáticos que afetam o desenvolvimento da cultura do feijão, a temperatura e precipitação pluviométrica ganham maior destaque. O Brasil é o maior produtor e consumidor de feijão-comum (Phaseolus vulgaris L.) no mundo, destacando-se o Paraná como o estado com a maior produção. Neste contexto, o objetivo deste trabalho é de reunir informações sobre as exigências agroclimáticas para a cultura do feijão, com base na bibliografia disponível.

Palavras chave: temperatura, disponibilidade hídrica, condições de solo.

\section{Agroclimatic Requirements for Common Beans (Phaseolus vulgaris L.)}




\begin{abstract}
The knowledge of the agroclimatic requirements of the crops is a tool that helps planning for agriculture, aiming at higher yield, profitability and reduction of losses due to climatic factors. Among the climatic elements that affect the development of common beans, the temperature and pluviometric precipitation gain greater prominence. Brazil is the largest producer and consumer of common beans (Phaseolus vulgaris L.) in the world, highlighting Paraná as the state with the largest production. In this context, the aim of this work is to gather information about the agroclimactic requirements for common beans, based on the available literature.
\end{abstract}

Keywords: temperature, water availability, soil conditions.

\title{
Introdução
}

De acordo com Vieira et al. (2006), o Brasil é o maior produtor e consumidor de feijãocomum (Phaseolus vulgaris L.) no mundo, destacando-se o Paraná como o estado com a maior produção. A produção na safra 2012/2013 no Brasil foi de 2.806.300 toneladas, com uma área plantada de 3.111.000 ha (COMPANHIA NACIONAL DE ABASTECIMENTO - CONAB, 2014).

De acordo com dados da CONAB (2014) a produtividade média do Brasil na safra 2012/2013 foi de $913 \mathrm{Kg} / \mathrm{ha}$, a qual é considerada baixa. Agricultores brasileiros que utilizam alta tecnologia na produção de feijão conseguem ultrapassar a marca de $3000 \mathrm{Kg} / \mathrm{ha}$. Entretanto, a maior parte do feijão brasileiro é produzida por pequenos agricultores com pouca tecnologia e geralmente adubação e controle de pragas deficientes (VIEIRA et al., 2006).

O conhecimento das exigências agroclimáticas das culturas é uma ferramenta que auxilia o planejamento agrícola, visando maior produtividade, rentabilidade e diminuição de perdas por fatores climáticos.

São inúmeros os fatores que influenciam o desempenho do feijoeiro, destacando-se a temperatura e precipitação. A temperatura é um dos fatores que afeta diretamente o desenvolvimento da cultura em diferentes estádios fisiológicos, principalmente o florescimento e a frutificação (MINISTÉRIO DA AGRICULTURA, PECUÁRIA E ABASTECIMENTO MAPA, 2012).

O objetivo deste trabalho é de reunir informações sobre essas exigências para a cultura do feijão, com base na bibliografia disponível, tendo em vista que o sucesso na produção de 
qualquer cultura começa pelo planejamento e conhecimento das exigências agroclimáticas da mesma.

\section{Exigências Agroclimáticas da Cultura do Feijão}

Dentre os elementos climáticos que afetam o desenvolvimento e produção da cultura do feijão, a temperatura e precipitação pluviométrica ganham maior destaque. As características físico-químicas do solo também influenciam no desenvolvimento do feijoeiro e devem ser levadas em consideração para o planejamento do cultivo (EMPRESA BRASILEIRA DE PESQUISA AGROPECUÁRIA - EMBRAPA, 2003).

\section{Temperatura}

A temperatura, dentre todos os fatores climáticos limitantes ao desenvolvimento do feijoeiro, é considerado o de maior influência no desenvolvimento de vagens, bem como sobre o florescimento e frutificação. Devido à diversidade térmica ao longo do território brasileiro, o cultivo do feijão é limitado em certas regiões, tanto pelas baixas temperaturas durante o inverno na região sul quanto pelas altas temperaturas associadas à altos índices de umidade ao norte, o que aumenta a incidência de doenças (EMBRAPA, 2003).

A temperatura média ideal para o cultivo na América Latina varia de 17,5 a $25^{\circ} \mathrm{C}$, procurando-se sempre o planejamento da semeadura para que a época de floração coincida com temperaturas próximas a $21^{\circ} \mathrm{C}$ (MARIOT, 1989 apud VIEIRA et al., 2006).

\section{Baixas Temperaturas}

Se temperaturas muito baixas ocorrerem logo após o período de semeadura do feijão, a germinação pode ser comprometida, diminuindo a população de plantas emergidas e refletindo na produtividade final. Isto ocorre porque quando a semente é lançada ao solo, esta apenas desencadeará o processo de germinação quando encontrar condições ideais de temperatura, umidade e luminosidade. Caso ocorra um período de baixas temperaturas após a germinação, quando a planta está na fase de crescimento vegetativo, seu crescimento será prejudicado, resultando em plantas de pequeno porte, também podendo ocorrer aborto de sementes (VIEIRA et al., 2006). 


\section{Altas temperaturas}

Altas temperaturas exercem maior influência no desenvolvimento de sementes e estruturas florais, entre outros processos fisiológicos danificados por este fator climático. $\mathrm{Na}$ presença de temperaturas muito elevadas, a planta começa o processo de abscisão dos órgãos reprodutivos, sendo que em temperaturas acima de $35^{\circ} \mathrm{C}$ praticamente não há formação de vagens, comprometendo significativamente a produção final (VIEIRA et al., 2006).

Segundo Portes (1988) apud Vieira (2006), a abscisão dos órgãos reprodutivos nestas condições está relacionada ao aumento da síntese de etileno, hormônio regulador de crescimento.

Altas temperaturas associadas à alta umidade aumentam a incidência de uma série de doenças que se desenvolvem ao encontrarem tais condições, as quais geralmente são ideais para sua propagação. Há regiões no Brasil em que é muito comum a ocorrência de altas temperaturas associadas a altos índices de precipitação durante a safra (VIEIRA et al., 2006).

\section{Constante térmica}

A relação entre a temperatura atmosférica e o desenvolvimento de determinada cultura é dada pela constante térmica, a qual é contabilizada pelo acúmulo de graus-dia. Esta relação baseia-se na quantidade de calor total que a planta necessita para completar certa etapa do seu desenvolvimento ou o seu ciclo completo, considerando que cada espécie tem uma temperatura mínima (basal) e uma máxima suportada para conduzir seus processos fisiológicos (BERLATO, 1981; SCHÖFFEL \& VOLPE, 2002 apud FILHO et al., 2003).

Segundo Mariot (1989) apud Filho et al. (2003), a temperatura-base considerada para o desenvolvimento do feijoeiro é de $10^{\circ} \mathrm{C}$, sendo a máxima de $35^{\circ} \mathrm{C}$. Em outro estudo conduzido com o cultivar carioca, Barbano (2003), encontrou valores de temperatura-base para tal cultivar entre 6,0 e $8,0^{\circ} \mathrm{C}$, bem como a necessidade de um total de 1218 graus-dia para o fechamento do ciclo do feijoeiro nas condições de avaliação.

A Tabela 1 traz as respectivas quantidades de graus-dia para cada etapa do ciclo da cultura do feijão, de acordo com estudo realizado por MEDEIROS et al., (2000).

Tabela 1. Tempo termal das fases fenológicas do feijoeiro, cultivar Carioca 80-SH, semeado nas populações de 14, 25 e 28 plantas m-2, em Campinas, 1994.

\begin{tabular}{lr}
\hline Fase fenológica & Graus-dia \\
\hline $1^{\mathrm{a}}$ folha trifoliada & 94 \\
$3^{\mathrm{a}}$ folha trifoliada & 246 \\
\hline
\end{tabular}

Revista Brasileira de Energias Renováveis, v. 3, p. 32-42, 2014 
Início do florescimento

Início da formação da vagem $\quad 653$

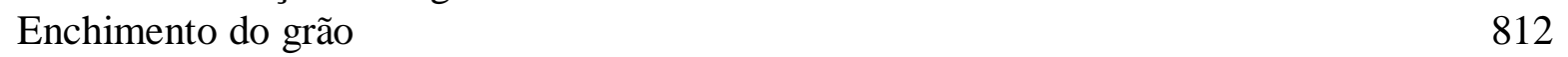

Colheita

1.155

Fonte: MEDEIROS et al., 2000.

\section{Umidade do Solo e Deficiência Hídrica}

A água é uma componente chave para o desenvolvimento de qualquer cultura, pois é responsável pelos processos básicos como fotossíntese, translocação de nutrientes e fotoassimilados, bem como na respiração e transpiração (GUIMARÃES, 1988 apud VIEIRA et al., 2006).

Desta maneira, o feijoeiro requer uma quantidade de água no solo que seja suficiente para o seu desenvolvimento e manutenção, sobretudo nas etapas mais fundamentais como germinação, emergência, floração e enchimento de grãos. A produção final pode ser comprometida logo nos primeiros dias caso ocorra falta de água nas fases inicias do desenvolvimento do vegetal, seguida de um período relativamente longo de estiagem. Estas condições afetarão sobretudo a fase de floração, consequentemente resultando em menor número de vagens e número de grãos por vagem (VIEIRA et al., 2006).

A deficiência hídrica é sentida a partir do momento em que a taxa de evapotranspiração é maior que a taxa de absorção de água pelas raízes. O feijoeiro apresenta um sistema radicular muito superficial quando comparado a outras culturas, possibilitando que pequenas estiagens ou longos intervalos de irrigação sejam sentidos mais rapidamente pela planta, por reduzir o conteúdo de água na camada superficial, diminuindo ou impedindo a absorção (VIEIRA et al., 2006).

Altas temperaturas e baixa umidade relativa do ar levam ao aumento da transpiração, aumentando a demanda de água pela planta, podendo prejudicar o número final de vagens e o enchimento de grãos (PORTES, 1988 apud VIEIRA et al., 2006).

Quando o déficit hídrico é sentido no período entre a semeadura e a emissão do quarto trifólio, visualmente percebe-se diminuição no número de plantas, acarretando menor produção de grãos (VIEIRA et al., 2006). Segundo Macedo Junior et al. (1994) apud Vieira et al. (2006), quando o feijoeiro é submetido a deficiência de água no solo nos primeiros 20 dias, pode-se verificar uma redução de 16 a $42 \%$ na produção de grãos quando comparado com a produtividade de uma planta em condições de campo de 0,01 MPa. 
O excesso de água no solo também pode causar danos à cultura do feijão. Esta condição pode ocorrer devido à drenagem deficiente ou abuso de irrigação, resultando na deficiência de oxigênio disponível no solo à planta e prejudicando a germinação, bem como o desenvolvimento e estabelecimento do sistema radicular do feijoeiro. Além disso, a umidade elevada propicia a incidência de patógenos que afetam as raízes, diminuindo a sobrevivência das plantas (VIEIRA et al., 2006). Segundo Silva (1982) apud Vieira et al. (2006), caso estas condições ocorram no período de florescimento e frutificação, há uma redução de 48 a $68 \%$ na produção. Quando incide na etapa de maturação da planta, o ciclo da cultura pode ser prolongado, atrasando a colheita. Também pode levar ao brotamento precoce, o que diminui a quantidade de grãos em condições de venda e/ou produção de sementes (VIEIRA et al., 2006).

\section{Precipitação Pluviométrica}

A precipitação pluviométrica, em conjunto com os demais fatores agroclimáticos, limita o crescimento e desenvolvimento do feijoeiro. Estima-se que o consumo hídrico da cultura do feijão seja de 300 a $600 \mathrm{~mm}$ ao longo de seus estádios de desenvolvimento, consumindo, em média, 3 a 4 mm por dia e necessitando de uma disponibilidade mínima de $100 \mathrm{~mm}$ mensais (DOURADO-NETO \& FANCELLI, 2000 apud MARCO et al., 2012).

Quando o feijão é cultivado sem irrigação, as chuvas precisam ser suficientes para suprir as exigências da planta sem que provoquem condições extremas de umidade. Durante o verão, a incidência de chuvas é suficiente para o crescimento e reprodução do feijão, entretanto, podem ocorrer eventos de excesso de umidade no solo. A incidência de chuvas durante a colheita também pode trazer prejuízos, aumentando o número de brotações e surgimento de manchas nas sementes durante a secagem em terreiros. Patógenos aéreos disseminam-se facilmente e doenças radiculares também são favorecidas pelo excesso de precipitação durante o crescimento do feijoeiro. Em geral, quando a semeadura é feita no final da época de chuvas, entre os meses de fevereiro e março, a umidade do solo mantem-se adequada para as fases vegetativas e de florescimento do feijoeiro. Contudo, a disponibilidade de água durante o enchimento de grãos pode ser baixa, resultando em perdas significativas no rendimento final (VIEIRA et al., 2006).

Em experimento realizado em Londrina/PR, Koguishi (2007), determinou que, para a semeadura do feijão das águas, i.e., plantado na época de chuva, em um solo com umidade abaixo do ponto de murcha permanente, a precipitação mínima necessária é de $40 \mathrm{~mm}$.

$\overline{\text { Revista Brasileira de Energias Renováveis, v. 3, p. 32-42, } 2014}$ 
De acordo com Silveira \& Stone (2001) apud Vieira et al. (2006), a época de semeadura, as características do cultivar, o local de cultivo e o manejo da cultura e do solo são fatores que influenciam diretamente na necessidade de água para se obter máxima produção.

\section{Zoneamento agroclimático}

O zoneamento agroclimático é uma ferramenta utilizada com o objetivo de evitar que intempéries climáticas venham a interferir no desenvolvimento das culturas, indicando a época mais adequada de plantio para cada região. Alguns dos parâmetros analisados para a definição do calendário de plantio são: temperatura, índices pluviométricos, dados de solo e ciclos das cultivares (MAPA, 2014).

As Figuras 1 e 2 mostram o zoneamento agroclimático para o plantio de feijão no estado do Paraná na $1^{\mathrm{a}}$ e $2^{\mathrm{a}}$ safras em solos de textura média (INSTITUTO AGRONÔMICO DO PARANÁ - IAPAR, 2014).

Figura 1. Zoneamento da cultura do feijão $1^{\mathrm{a}}$ safra em solos de textura média no Paraná.

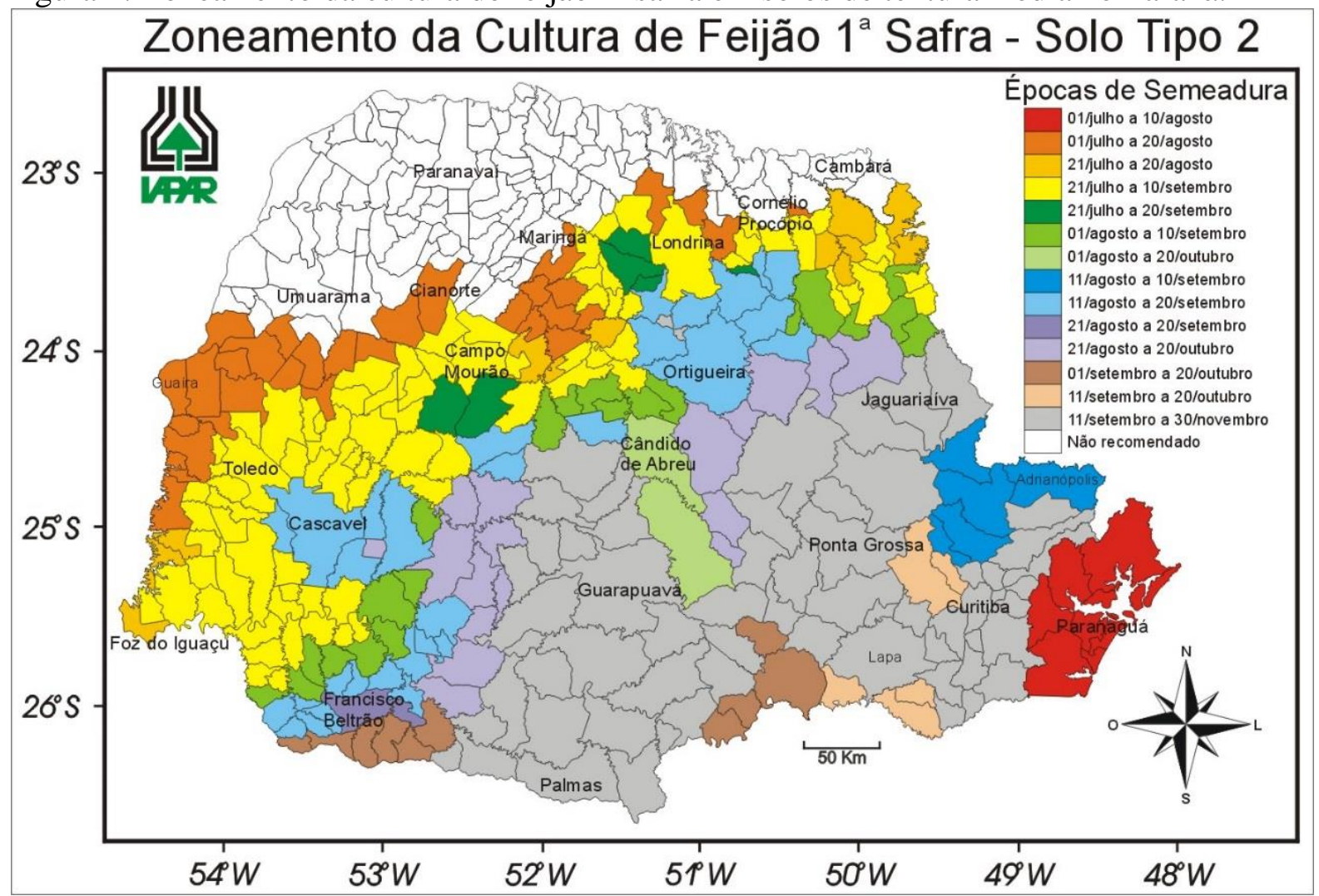

Fonte: IAPAR, 2014. 
Figura 2. Zoneamento da cultura do feijão $2^{\mathrm{a}}$ safra em solos de textura média no Paraná.

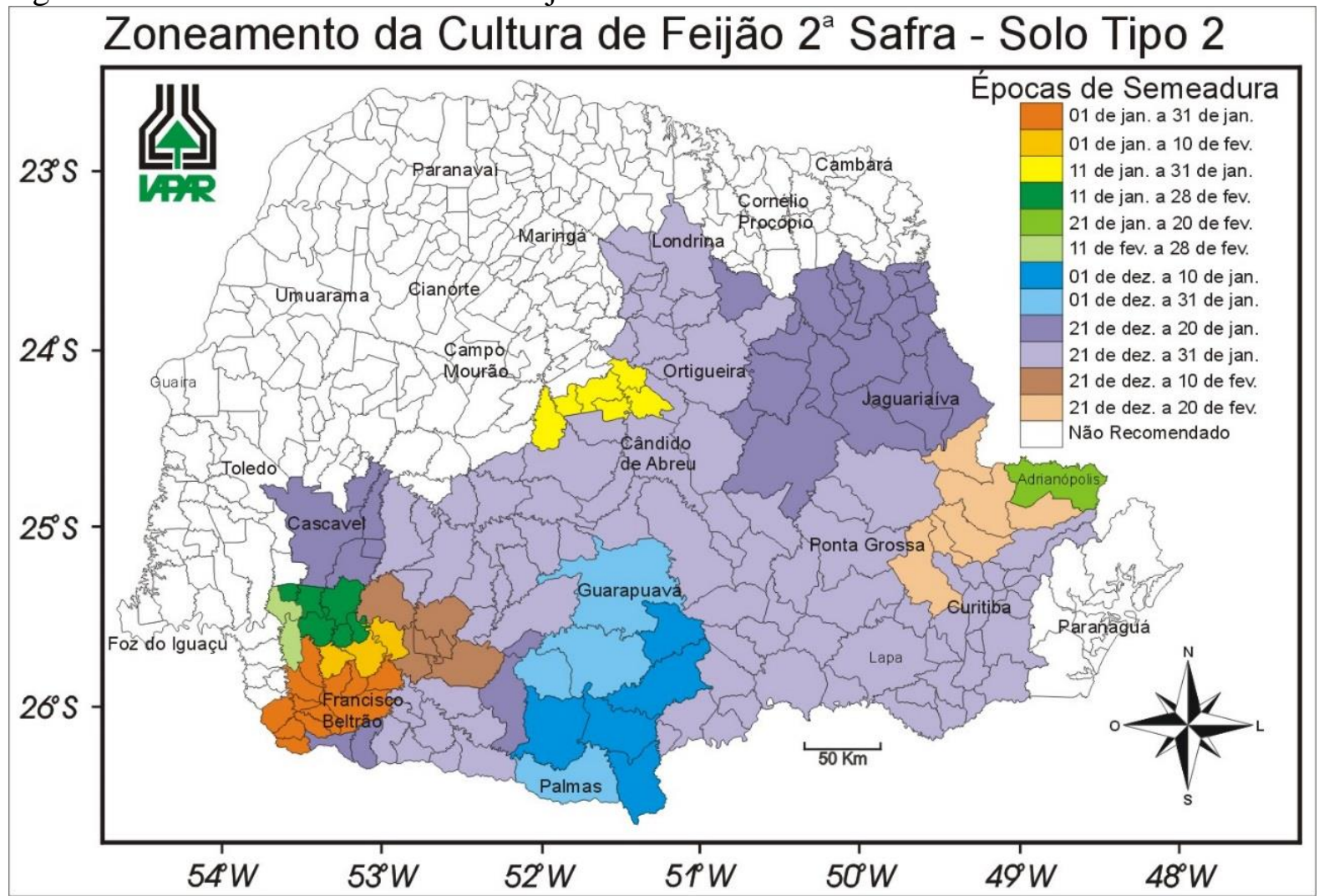

Fonte: IAPAR, 2014.

Solo

De acordo com Wallace (1980) apud Vieira et al. (2006), o feijoeiro adapta-se a diferentes condições de textura de solo, desde levemente arenosos até altamente argilosos. Entretanto, áreas de baixadas sujeitas a inundação e solos mal drenados devem ser evitados em épocas de altos índices pluviométricos, dando-se preferência ao cultivo em áreas mais elevadas e bem drenadas. Solos argilosos também apresentam maiores probabilidades de compactação subsuperficial e formação de crostas na superfície, bem como propiciam a ocorrência de fungos que atingem o sistema radicular.

Outro fator condicionador de estabilidade e sobrevivência da cultura após a germinação é a compactação do solo. Os fatores físicos do solo determinam a capacidade de penetração do sistema radicular da planta (MODOLO et al., 2011).

A compactação ocorre principalmente pelo tráfego de máquinas e implementos agrícolas pesados, resultando na diminuição da aeração do solo e queda no fluxo de água, conforme Alves et al. (2003) apud Vieira et al. (2006). A compactação pode ser agravada quando o solo encontra-se em condições de umidade muito altas. Solos argilosos são os mais 
afetados devido às suas partículas minúsculas que podem se aproximar muito umas das outras, tornando o solo mais denso e menos poroso, o que dificulta a penetração da água e as trocas gasosas com a atmosfera (MAGDOFF et al., 2009).

Em experimento realizado por Modolo et al. (2011) a aplicação de forças compactadoras no solo não diferenciaram significativamente no número de emergência de plântulas. Por outro lado, segundo experimento feito por Alves et al. (2001) apud Vieira et al. (2006), o aumento gradativo da compactação no solo provocou diminuição da massa seca de raízes e da parte aérea, refletindo em um menor número de vagens.

Em condições de clima adequado e ausência de problemas de compactação do solo, as características químicas do solo governam o desenvolvimento do feijoeiro. O solo deve ser capaz de fornecer os nutrientes necessários para o bom desenvolvimento da cultura, bem como possuir valores de pH apropriados (MORAES, 1988 apud VIEIRA et al., 2006).

De acordo com dados da Embrapa (2005), a faixa de pH ótimo para o cultivo do feijoeiro é de 5,8 a 6,2. A disponibilidade de nutrientes é muito importante para o cultivo do feijoeiro, especialmente logo após a germinação. O déficit nutricional durante os primeiros dias após a semeadura pode comprometer o crescimento radicular e, por conseguinte, o desenvolvimento das plantas (VIEIRA et al., 2006).

A salinidade do solo é outro fator que pode influenciar diretamente na produção do feijoeiro, pois este é muito sensível à altas concentrações de sódio e elevada condutividade elétrica (VIEIRA et al., 2006). A prática de irrigação em excesso e/ou a utilização de águas salinas para a irrigação pode elevar a concentração de sais e a condutividade elétrica da camada de solo em contato com as raízes do feijoeiro, levando à redução na produção final da cultura (SOUZA, 1995 apud VIEIRA, 2006).

\section{Considerações Finais}

Através do presente estudo verificou-se que o feijão é uma cultura exigente quanto às características agroclimáticas do local de cultivo. Desta forma, o conhecimento das particularidades da área a ser utilizada para a implantação da cultura faz-se essencial como ferramenta para evitar perdas e maximizar a produção e rentabilidade. 


\section{Referências}

ALVES, V. G.; ANDRADE, M. J. B.; CORRÊA, J. B. D.; MORAES, A. R.; SILVA, M. V. Crescimento e produção de vagens do feijoeiro em direrentes graus de compactação e classes de solos. Ciência e agrotecnologia, Lavras, v. 25, n. 5, p. 1051-1062, set./out., 2001.

ALVES, V. G.; ANDRADE, M. J. B.; CORRÊA, J. B. D.; MORAES, A. R.; SILVA, M. V. Concentração de Macronutrientes na parte aérea do feijoeiro (Phaseolus vulgaris L.) em função da compactação e classes de solos. Ciência e agrotecnologia, Lavras, v. 27, n. 1, p. 44-53, jan./fev., 2003.

BARBANO, M. T. Riscos Climáticos e Épocas de Semeadura para o Feijoeiro (Phaseolus vulgaris 1. Cv. Carioca) na Safra das Águas no Estado de São Paulo. 2003. Dissertação (Mestrado em Agricultura Tropical e Subtropical) - Instituto Agronômico de Campinas, Campinas - SP.

BERLATO, M.A. Exigências bioclimáticas e zoneamento agroclimático. In: MIYASAKA, S.; MEDINA, J.C. (Ed.). A soja no Brasil. Campinas: ITAL, 1981.

CONAB - Companhia Nacional de Abastecimento. Indicadores da Agropecuária. Brasília, ano XXII, n. 4, 2014. Disponível em: <http://www.conab.gov.br/OlalaCMS/uploads/arquivos/ 14_04_30_11_38_00_revista_abril_versao_final.pdf $>$. Acesso em: 16 de maio de 2014.

DOURADO NETO, D.; FANCELli, A. L. Produção de feijão. Guaíba: Agropecuária, 2000, $385 \mathrm{p}$.

EMBRAPA - Empresa Brasileira de Pesquisa Agropecuária. Embrapa Arroz e Feijão. Cultivo do Feijoeiro Comum. Sistemas de Produção. Versão Eletrônica. 2003. Disponível em: $<\mathrm{http}$ ///sistemasdeproducao.cnptia.embrapa.br/FontesHTML/Feijao/CultivodoFeijoeiro/clima. htm>. Acesso em: 16 de maio de 2014.

EMBRAPA - Empresa Brasileira de Pesquisa Agropecuária. Embrapa Rondônia. Cultivo do Feijoeiro Comum em Rondônia. Sistemas de Produção. Versão Eletrônica. 2005. Disponível em: <http://sistemasdeproducao.cnptia.embrapa.br/FontesHTML/Feijao/CultivodoFeijaoCom umRO/clima.htm>. Acesso em: 16 de maio de 2014.

FILHO, J. F.; NOBREGA, J. Q.; RAO, T. V. R. Necessidades Térmicas do Feijoeiro em Regime de Sequeiro. Lagoa Seca, 2003.

GUIMARÃES, C. M. Efeitos fisiológicos do estresse hídrico. In: ZIMMERMANN, M. J. O.; ROCHA, M.; YAMADA T. (Ed.). Cultura do feijoeiro: Fatores que afetam a produtividade. Piracicaba: Associação Brasileira para Pesquisa da Potassa e do Fosfato, 1988.

IAPAR - Instituto Agronômico do Paraná. Zoneamento da Cultura de Feijão. Disponível em: <http://www.iapar.br/modules/conteudo/conteudo.php?conteudo=1092>. Acesso em: 16 de maio de 2014.

KOGUISHI, Mirian Sei. Precipitação mínima para a semeadura de soja e feijão das águas em Londrina, Paraná. 2007. Dissertação (Mestrado em Agronomia) - Universidade Estadual de Londrina, Londrina - PR.

MACEDO JÚNIOR, E.K.; FARIA, M.A. de; SOARES, A.M. Produção do feijoeiro (Phaseolus vulgaris L.) submetido a cinco níveis de tensão de água no solo. Ciência e Prática, Lavras, v.18, n.4, 1994. 
MAGDOFF, F.; VAN ES, H. Building Soils for Better Crops. 3 ed. Waldorf: Sustainable Agriculture Research and Education, 2009.

MARCO, K.; DALLACORT, R.; JÚNIOR, C. A. F.; FREITAS, P. S. L.; VILLELA, T. G. Aptidão Agroclimática e Características Agronômicas do Feijão-Comum Semeado na Safra das Águas em Tangará da Serra - MT. Enciclopédia Biosfera. Goiânia, v. 8, n. 15, p. 160, 2012.

MARIOT, E.J. Ecofisiologia do Feijoeiro. In: IAPAR (Ed.). O feijão no Paraná. Londrina: IAPAR, 1989.

MAPA - Ministério da Agricultura, Pecuária e Abastecimento. Perfil do feijão no Brasil. Disponível em: <http://www.agricultura.gov.br/vegetal/culturas/feijao/saiba-mais>. Acesso em: 16 de maio de 2014.

MEDEIROS, G. A.; ARRUDA, F. B.; SAKAI, E.; FUJIWARA, M.; BONI, N. R. Crescimento vegetativo e coeficiente de cultura do feijoeiro relacionados a graus-dia acumulados. Pesquisa Agropecuária Brasileira. Brasília, v. 35, n. 9, Set. 2000. Disponível em: $<$ http://www.scielo.br/scielo.php?script=sci_arttext\&pid=S0100-204X2000 $000900005 \& \operatorname{lng}=e n \& n r m=i s o>$. Acesso em: 23 de maio de 2014.

MODOLO, A. J.; TROGELlO, E.; NUNES, A.L.; SILVEIRA, J. C. M.; KOLLING, E. M. Efeito da Compactação do Solo Sobre a Semente no Desenvolvimento da Cultura do Feijão. Acta Scientiarum. Agronomy. Maringá, v. 33, n. 1, 2011.

MORAES, J.F.N. Calagem e Adubação. In: ZIMMERMANN, M. J. O.; ROCHA, M.; YAMADA T. (Ed.). Cultura do feijoeiro: Fatores que afetam a produtividade. Piracicaba: Associação Brasileira para Pesquisa da Potassa e do Fosfato, 1988.

PORTES, T. A. Ecofisiologia. In: ZIMMERMANN, M. J. O.; ROCHA, M.; YAMADA T. (Ed.). Cultura do feijoeiro: Fatores que afetam a produtividade. Piracicaba: Associação Brasileira para Pesquisa da Potassa e do Fosfato, 1988.

SCHÖFFEL, E. R.; VOLPE, C. A. Relação entre a soma térmica efetiva e o crescimento da soja. Revista Brasileira de Agrometeorologia, Santa Maria, v. 10, n. 1, 2002.

SILVA, E. L. Suscetibilidade do feijoeiro (Phaseolus vulgaris L.) cv. goiano precoce a inundações temporárias do sistema radicular em diferentes fases do seu ciclo vegetativo. 1982. Tese - ESALQ, Piracicaba-SP. 76 p.

SILVEIRA, P. M.; STONE, L. F. Irrigação do feijoeiro. Santo Antônio de Goiás: Embrapa, 2001.

SOUZA, M. R. de. Comportamento do feijoeiro (Phaseolus vulgaris L. CV Eriparza) submetido a diferentes níveis de salinidade da água de irrigação. 1995. 94 p. Dissertação (Mestrado em Engenharia Agrícola) - Universidade Federal de Lavras, Lavras.

VIEIRA, C.; JÚNIOR, T. J. P.; BORÉM, A. Feijão. 2 ed. Viçosa: UFV - Universidade Federal de Viçosa, 2006. 600p. 